\title{
Dynamic capabilities as (workable) management systems theory ${ }^{1}$
}

\section{David J Teece}

\begin{abstract}
In management studies, systems theory is an underexplored construct consistent with the dynamic capabilities framework. The systems approach received attention from management scholars in the middle of the last century, but, since then, has been largely abandoned. Meanwhile, academic disciplines have continued to narrow their focus. The capabilities and systems frameworks both adopt a holistic view that calls for all elements of an organization to be in alignment, and both recognize the importance of some form of learning for the purpose of adaptation. Dynamic capabilities go further by recognizing that organizations not only adapt to the business environment, they often try to shape it, too. While systems theory emphasizes internal stability over time and homogeneity across similar systems, dynamic capabilities include an explicit role for management/leadership that allows systemic change to start from within, which is the source of heterogeneity across firms. Dynamic capabilities are part of a system that includes resources and strategy. Together they determine the degree of competitive advantage an individual enterprise can gain over its rivals.
\end{abstract}

Keywords: dynamic capabilities, systems theory, complex systems, VRIN resources, strategy

Received 27 November 2017. Accepted 29 November 2017

\section{INTRODUCTION}

$\mathrm{M}$ uch has been written about the dynamic capabilities framework. A title search in Google Scholar returns nearly 3,000 articles, and an 'anywhere' search yields tens of thousands more. Yet relatively little has been written about the framework's relationship to one of its antecedents, systems theory. This essay will address that lacuna.

I arrived at U.C. Berkeley's business school in 1982, a year after the official retirement of C. West Churchman, one of the pioneers of system science. Churchman was still a presence on campus, teaching classes in conflict studies, and his influence remained strong in the business school, not least in the field of management science, which he did so much to establish.

While the application of systems theory to management had largely run its course by the 1980 s, I remained intrigued by its potential for providing a holistic view of the business enterprise. The basic idea is that a complex system is 'made up of a large number of parts that interact in a nonsimple way. In such systems, $\ldots$ it is not a trivial matter to infer the properties of the whole' (Simon, 1962: 468).

Institute for Business Innovation, Haas School of Business, University of California, Berkeley, Berkeley, CA, USA Corresponding author: teece@haas.berkeley.edu

1 This paper is based on a presentation delivered at the Academy of Management Annual Meeting, Atlanta, GA, August 7, 2017. 
While a systems approach was a helpful reminder not to get lost in the details, it lacked an ability to account for critical aspects of what made some firms so much more nimble and successful longer term than their rivals. Nor did it provide much guidance for managers such as identifying cause and effect relationships and pinpointing the most critical linkages.

Systems theory was one of the influences in the back of my mind when I began working on the dynamic capabilities framework, the earliest version of which was initially released as a working paper with two doctoral students in 1990 (Teece, Pisano, \& Shuen, 1990). I did not cite Simon then, but I was very much (and remain) influenced by the Carnegie School tradition and accepted the importance of multidisciplinary and interdisciplinary research.

Dynamic capabilities were defined as 'the firm's ability to integrate, build, and reconfigure internal and external competences to address rapidly changing environments' (Teece, Pisano, \& Shuen, 1997: 516), a definition which still more or less applies, although the speed of change in the environment may be less relevant than the prevailing degree of uncertainty (Teece, Peteraf, \& Leih, 2016). As scholars in the field of strategic management have put considerable effort into identifying and testing various aspects of dynamic capabilities, attention has been drawn away from the overall need to keep the elements aligned internally. This essay, by emphasizing the links between dynamic capabilities and system-level thinking, seeks to redress the imbalance.

The paper begins with a summary of systems theory and its limits with respect to strategic management. The dynamic capabilities framework is then presented as a form of applied systems theory that allows for managerially induced discontinuities. A conclusion offers some final reflections on the systems and dynamic capabilities approaches.

\section{SYSTEMS THEORY}

Systems theory is a framework that was devised to enable a holistic approach to the investigation of phenomena across a range of disciplines. The core idea, which dates back to Aristotle, is that the whole is more than the sum of its parts. ${ }^{2}$ In other words, a proper understanding of a system cannot be reached by studying its components in isolation from one another (reductionism) any more than a pile of feathers and organs could be assembled into a living bird.

General systems theory emerged from separate research streams in biology (von Bertalanffy), cybernetics (Wiener), economics (Boulding), and mathematics (Rapaport) that were each developing similar models of internal interdependencies and feedback loops. The founders of systems theory hoped that it would lead to the 'unification of science' (von Bertalanffy, 1950: 165).

In an early issue of the journal Management Science, economist Kenneth Boulding made the case for a systems theory approach to management (Boulding, 1956). Systems theory gained currency in management research in the 1960s and remained quite influential through the 1970s (Ashmos \& Huber, 1987). Burns and Stalker (1961), for example, made substantial use of a systems approach in setting forth their concepts of mechanistic and organic managerial systems.

The logic of systems theory was eventually incorporated into a widely used congruence theory of organizational alignment by Nadler and Tushman (1980). It is still invoked at times by management scholars who want to emphasize the integrated nature of the elements in a model (e.g., Samuel \& Jacobsen, 1997; O’Connor, 2008).

Systems theory views organizations as social systems made up of sub-units that must inter-relate in a harmonious (congruent) manner for the organization to be effective (Johnson, Kast, \& Rosenzweig, 1963;

2 'In the case of all things which have several parts and in which the totality is not, as it were, a mere heap, but the whole is something beside the parts, there is a cause' (Metaphysics, Book VIII, W. D. Ross translation. http://classics.mit.edu/ Aristotle/metaphysics.8.viii.html 
Churchman, 1968). The systems theory approach thus focuses on the complementarities among elements, their integration, and the outcomes resulting from their interactions. In the case of an 'open system' such as the business enterprise, the theory also encompasses the system's interactions with its environment. Feedback loops enable adaptation to environmental changes.

Systems are generally nested and networked, with sub-units being systems in their own right. A single firm, which can be analyzed as a system, is part of a larger industrial/business ecosystem, and it can also be viewed as networked with other firms in its value chain. Within the firm exist many sets of activities, such as production, marketing, etc., each of which can be analyzed as a system connected to other systems internally and externally. Nesting also occurs with regard to technologies. Any complex technological product, such as a PC, is a system that contains sophisticated components, many of which are systems in their own right.

Dynamic capabilities, which will be described later in more detail, exhibit nesting to some extent. For example, while dynamic capabilities are most often analyzed at the corporate level, they are also important at the business unit and product levels. They can even be said to exist at the level of the individual manager, in the form of 'dynamic managerial capabilities' (Adner \& Helfat, 2003).

While a holistic view is systems theory's most obvious feature, a systems approach does not neglect the study of individual elements. Both levels must be understood. A business model, for example, involves a product or service, a pricing logic, a geography of distribution, etc. (Teece, 2017). These elements may or may not be chosen or developed separately from each other. But, however they are brought into play, the elements of the model must be coherently aligned and linked to an astute strategic vision if they are to lead to profits. If an element doesn't fit properly, e.g., if productive capabilities are inadequate to reach the expected product quality and/or volume, then the model will not perform as desired. Dynamic capabilities can also be broken down into elements (microfoundations). This was the focus of my article 'Explicating dynamic capabilities' (Teece, 2007).

A holistic approach does not vitiate Simon's notions of 'near decomposability' and technologically separable business units. In the short run, behavior in one subsystem or silo is approximately independent of the others. As time passes, though, that may no longer be true.

Systems theory also recognizes the importance of feedback, which is analogous to learning in the business enterprise. A simple feedback loop involves information about external changes coming into the system, whose components adjust to the environment while keeping all of the interdependent internal elements in balance and in line with existing plans. But feedback can also trigger double-loop learning, where the managers of the system respond by adjusting their mental models and plans to take account of external changes (Argyris, 1976). A system with double-loop learning does not maintain a steady state as the environment changes; it establishes a 'flowing equilibrium' in which internal alignment is maintained but the overall state of the system changes (Felix, 2003).

\section{THE LIMITS OF SYSTEMS THEORY FOR MANAGEMENT}

A strength of systems theory is its multidisciplinary approach. As it sought to unify various disciplines, systems theory drew on their concepts. Such multidisciplinarity runs against the grain of modern academia, even within the business school (Teece, 2011). Academics today are rewarded for deep specialization, and this shapes the way managers are trained. When they enter university-based programs, academics and practitioners alike do an admirable job of analyzing problems of accounting, marketing, operations, manufacturing, or strategy as separate activities. But this leads to a partialsystem view and, in some cases, erroneous conclusions. For example, responding to a decline in demand only by reducing production costs might provide short-term improvement while missing a strategic shift with far more important long-term implications. 
Still, from the perspective of strategic management, systems theory has several limitations. Herbert Simon (1962: 482) warned half a century ago that if systems theory was going to be more than a fad, then it would need to 'provide substance to go with the name.' That substance has been slow in coming. Perhaps one reason is that systems theory has been hobbled by its origins in the domains of biology and system control, where there is an absence of the human element and hence of design. As has long been recognized, physical analogies 'miss the essential social-psychological facts of the highly variable, loosely articulated character of social systems' (Katz \& Kahn, 1978: 37).

For example, the homeostatic equilibrium of living organisms that inspired systems theory is efficient, but not necessarily effective. Effectiveness, particularly with regard to permanent changes in the environment, requires an ability to transform. The dynamic capabilities framework recognizes the importance of bottom up innovation, either as the creation of new knowledge (e.g., Nonaka, 1994) or the pursuit of breakthrough (non-evolutionary) new products. While these phenomena can be studied through a systems theory lens (O'Connor, 2008), the dynamic capabilities framework leads more naturally to such activities.

Another concept in general systems theory that marks a shortcoming with respect to dynamic capabilities is equifinality, the idea that different systems can achieve an identical outcome with different combinations of conditions and paths. There is unquestionably truth in this; companies, for example, have adopted several different business models for making and selling smartphones. However, equifinality emphasizes the substitutability of firms and their strategies, whereas the dynamic capabilities framework emphasizes that heterogeneity is meaningful and supports competitive differentiation.

This gap has been partially bridged by the growing interest of management scholars in complex systems, which combine elements of chaos theory with a systems theory approach (Schneider \& Somers, 2006). Some degree of complexity was recognized early on as an element of general systems theory. Boulding (1956: 202) offered a nine-level 'hierarchy of complexity' consisting of system types ranging from relatively static atomic systems inside inanimate objects all the way up to social organizations (topped by a ninth, unknown 'transcendental' level). Simon was, of course, also interested in complexity theory.

A related variation is the theory of complex adaptive systems (Holland, 1992; Anderson, 1999). While complex systems are still basically deterministic in nature, following system-level rules, complex adaptive systems are understood from the bottom up, built from interactions of the individual elements. In successful firms facing high-velocity environments, interactions in a complex adaptive system are often improvised and loosely structured, which is consistent with the dynamic capabilities approach (Brown \& Eisenhardt, 1997).

Complex systems produce chaotic outcomes such as emergent properties and are prone to large changes in outcome as a result of small changes in the relevant variables. These path-dependent outcomes are in keeping with the dynamic capabilities framework's emphasis on unique pathdependent outcomes. However, the so-called 'butterfly effect' (small causes inducing large changes) probably has more relevance to the external environment than to intra-organizational evolution. Nevertheless, because long-term forecasting is unlikely to be useful, the theory of complex systems points to the need to develop organizational flexibility and resilience, which is very much in line with the dynamic capabilities view (Levy, 1994).

For practitioners, a key defect of systems theory is that it is not inherently prescriptive. The goal of firms is not just survival, but prosperity. While certain lessons for practitioners can be drawn from applying a systems approach, such as 'Consider the technostructural character of higher level system components (departments, supraprograms) in planning change' (Rousseau \& Cooke, 1984: 358), they remain rather abstract. There is no systems theory toolkit for managers. An awareness that everything is 
inter-related is of limited use. Managers need to know which relationships are most critical at a particular juncture. Simon's 'near decomposability' approach started to get to these issues, but provided few, if any, guidelines.

In fact, managers are only seen in systems theory as parts of the whole, not as purposive human elements capable of exercising their own will and design capabilities. The systems approach lacks a place for proactive entrepreneurial action, viewing the system as primarily seeking to remain aligned with the survival requirements of the mega-system in which it is embedded. This purely reactive stance suppresses the major thrust of strategic management.

To summarize, general systems theory, with its biological orientation and emphasis on reactivity, is consistent with an evolutionary view of the firm (Nelson \& Winter, 1982). Strategic management, however, calls for a framework that recognizes both evolution (path dependence) and design (entrepreneurship). The dynamic capabilities framework, which I next present in more detail, combines both these strands (Augier \& Teece, 2008).

\section{DYNAMIC CAPABILITIES AS A WORKABLE SYSTEMS THEORY}

The dynamic capabilities framework was created to help organize and prioritize the endless stream of competing and conflicting information that cascades toward managers as they attempt to build competitive advantage. The goal is not short-term efficiency, as in classic management, but rather the maintenance of 'evolutionary fitness' over time (Teece, 2007). To accomplish this, the firm must create an ability to respond rapidly and effectively not only to threats in the business environment but also to opportunities (Teece, Pisano, \& Shuen, 1997).

This section describes the framework in more detail, beginning with the capabilities hierarchy at its heart. Capabilities determine what the firm is able to do and how effectively it can make changes. This section also provides a systemic view of the full framework. As shown in Figure 1, other components of the framework include firm resources, strategy, and external firms and institutions.

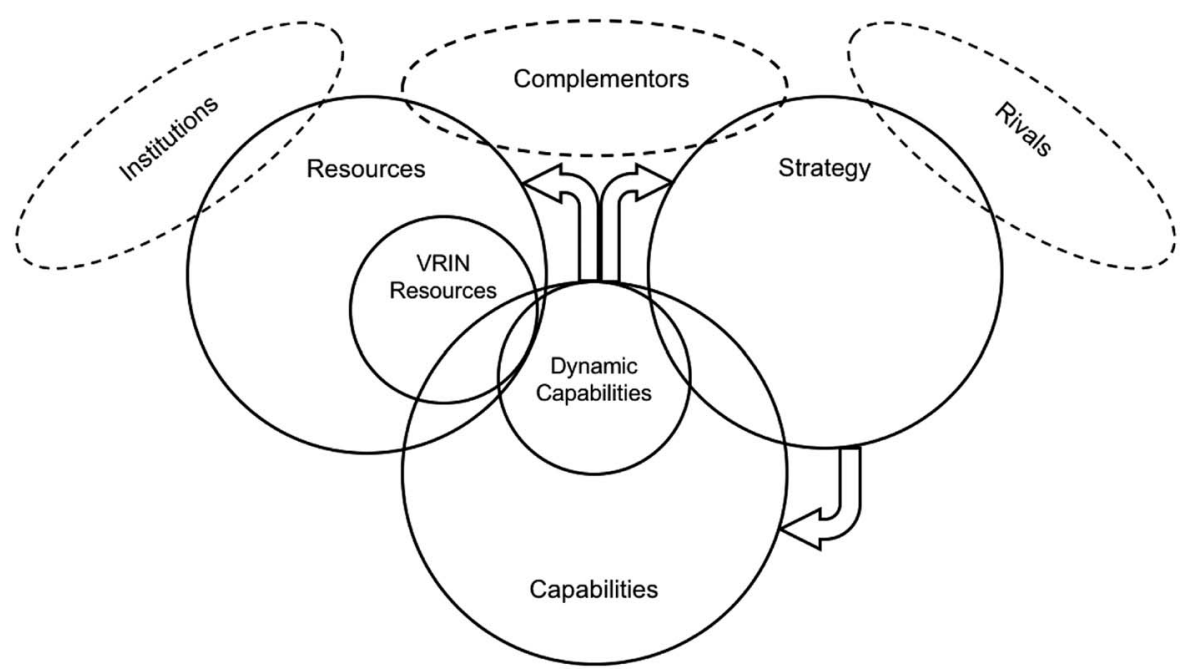

Figure 1. The key elements of the dynamic CAPABILITIES Framework

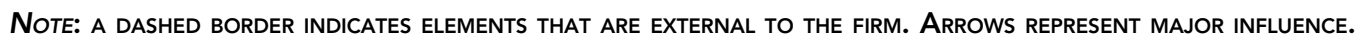
VRIN = VALUABLE, RARE, IMPERFECTLY IMITABLE, AND NON-SUBSTITUTABLE 


\section{Capabilities: A nested hierarchy}

The core of the framework is the capability hierarchy, itself a system of nested elements and activities. At the base of the capability hierarchy lie ordinary capabilities. Ordinary capabilities consist of the processes that deploy people, facilities, and equipment to carry out the current business of the firm. Strong ordinary capabilities allow a firm to achieve best-practice levels of efficiency, regardless of whether the current output plan is likely to be suitable in the future. They lend themselves to being measured and benchmarked, which also makes them easier to replicate. For this reason, they are an unreliable basis for long-term advantage.

Management's approach toward ordinary capabilities can have systemic effects. The relentless pursuit of efficiency in operational tasks can drive out the capacity to change. It's easiest to maintain peak efficiency when tasks remain fixed. High efficiency, without accompanying measures to mitigate risk and an organizational culture that enables rapid improvisation, can deprive a company of the resilience needed to change promptly when the need arises. The vulnerability of just-in-time supply chains to a sudden shortage in the supply of even a minor part is a case in point. When a lightning strike forced a New Mexico microchip factory offline for weeks in 2000, Ericsson, which relied on the factory, lost an estimated US\$ 400 million in revenue (Latour, 2001). By contrast, Nokia's supply chain team, which also depended on the factory, patched together a solution that kept its production on target.

The next level of the capability hierarchy consists of 'microfoundations' (Teece, 2007). These are lower-level dynamic capabilities such as processes for forming external partnerships or for developing new products. They consist of (often idiosyncratic) routines that are employed less often than the routines of ordinary capabilities. Microfoundations allow the firm to integrate, reconfigure, add, or subtract resources, including ordinary capabilities (Eisenhardt \& Martin, 2000).

The higher-level dynamic capabilities are activities and assessments that channel other capabilities and resources so as to maintain external fitness. They can be summarized as three clusters of entrepreneurial activities that take place concurrently throughout the organization: sensing, seizing and transforming. They encompass organizational processes as well as unique managerial decisions (Augier \& Teece, 2009; Teece, 2012, 2016).

The activities for 'sensing' include environmental scanning, which brings disorganized information and unstructured data from the external environment into the organizational system. Managers at various levels must generate and test hypotheses about latent consumer demand, technological possibilities, and other forces that affect the firm's future. The system must allow relevant information to find its way to where it will be properly assessed and handled. An effective intra-organizational network requires decentralizing authority, creating a collaborative organizational culture, and propagating a shared vision. The top management team can use the data from internal and external sources to continuously monitor the firm's environment, prioritize problems, and identify new opportunities.

'Seizing' capabilities determine how quickly the system can respond to opportunities and threats once they have been identified and deemed important. The activities involved include investing to commercialize new technologies and designing (or updating) and implementing business models for various products and services. The business model for a line of business includes the activities to be undertaken, the internal incentives to be used, the design of customer interactions, and more (Teece, 2017). It is essentially a vertical slice of the firm's activities and has the same systemic need as the entire firm for all its elements to be kept in alignment.

'Transforming' capabilities are responsible for keeping the elements of the organizational system aligned both with each other and with the strategy. These capabilities are most critical when a new business model involves a significant change to the organization's design or conflicts with an existing business model. This is often the case, for example, when an established firm adopts a digital business model that risks cannibalizing existing sales. Minor transformations must also be made periodically to 
keep the organization aligned with its environment. Fostering an organizational culture that favors flexibility and experimentation, while challenging to bring about, can provide a firm foundation for quicker and easier transformations and, therefore, for future advantage.

\section{The dynamic capabilities framework as a system}

The two other main components of the dynamic capabilities framework are resources and strategies. Resources include employees, equipment, buildings, and intangible assets. Many resources are generic, meaning that they can be replaced if needed via a market transaction. The more important type of resource satisfies the criteria defined by Barney (1991): valuable, rare, imperfectly imitable, and non-substitutable (VRIN). VRIN resources can support durable competitive advantage. They are most often intangible (e.g., a valuable brand name) in part because most intangible assets have poorly defined property rights, which makes them virtually non-tradable and therefore difficult to acquire (Teece, 2015).

The concept of VRIN resources has been used to argue that the ownership and management of strategic resources are the key to competitive advantage. This resource-based view of strategic management (e.g., Wernerfelt, 1984), a forerunner to dynamic capabilities, had a broad influence in strategic management but always suffered from providing only a partial-system approach to building competitive advantage (Priem \& Butler, 2001). While resources can include (at least some) capabilities, the resources approach has no specificity about the capabilities required to excel other than the VRIN criteria. Another weakness of the resource-based view is its lack of attention to how a firm's key resources can be renewed when circumstances require it.

The final major component of the dynamic capabilities framework is strategy. Whereas capabilities are primarily about what to produce and how and where to make, market, and distribute it, strategy helps to determine the timing of market entry and how to keep competitors at bay. The goal of strategy is to outmaneuver competitors by taking advantage of their mistakes and leveraging in-house strengths. It is the purview of strategy theories such as Five Forces (Porter, 1980) and isolating mechanisms (Rumelt, 1987).

A strategy can be defined as 'a coherent set of analyses, concepts, policies, arguments, and actions that respond to a high-stakes challenge' (Rumelt, 2011: 6). According to Rumelt (2011), a good strategy has (1) prescient diagnoses that identify obstacles, (2) a guiding policy that specifies an approach to overcoming them, and (3) a coherent plan of action that implements the policy. A good strategy will often not appear fully formed, but instead emerge over a period of trial and error (provided the business environment is sufficiently forgiving to allow experimentation). While the actions dictated by the strategy will be visible to rivals and freely imitable, the underlying diagnosis and policy can be kept secret. Rivals may not believe it is in their interest to copy a strategy until it is too late.

Capabilities, resources, and strategy constitute a system of interdependent elements that collectively determine the competitiveness of a firm. Competitive advantage is enhanced when the firm-level elements are strong and in alignment with each other and the external situation. This insight also follows from an application of systems theory known as the congruence model (Nadler \& Tushman, 1980, 1997). However, key elements of that model were underdeveloped. Internally, the model's system of resources, tasks, and goals inside the firm lacked any reference to a business model, which must also align with the organization and with its strategy (Teece, 2014). A business model in which cost and revenue are inconsistent, or which requires capabilities the firm lacks, will not be profitable or sustainable.

To capture this interdependence, the dynamic capabilities framework adopts the language of cospecialization rather than congruence (Teece, 1986, 2010). Cospecialization describes the extra value generated by a set of two or more assets when they're used jointly rather than in isolation. Congruence 
is far more important for cospecialized assets than for separable (modular) assets. Many operational (ordinary) activities have this separable quality and can be outsourced.

The three elements of the capabilities framework - resources, capabilities, and strategies - are each vital for competitive advantage. Without strong dynamic capabilities, VRIN resources, and good strategy, any advantage is likely to be unsustainable. The dynamic capabilities that are core to enhancing processes and exploiting possibilities must be guided and informed by strategy - and viceversa. Firms with weaker capabilities require different strategies than firms with stronger capabilities. And the effectiveness of dynamic capabilities will be compromised by poor strategy.

To summarize, the strength of a firm's dynamic capabilities determines the speed and degree to which the firm's idiosyncratic resources can be aligned and re-aligned consistent with the firm's strategy. Because of their strong interdependencies, the three elements of the framework can be hard to tease out for research purposes. Although conceptually distinct, they overlap in practice, as shown schematically in Figure 1. For example, resources include 'managerial services,' which would logically also be part of a firm's dynamic capabilities. Similarly, the sensing activities of dynamic capabilities can be identical to the 'problem diagnosis' step of the strategy making process.

\section{CONCLUSION}

The systems theory approach to management lends itself to disciplined generalizations but limited deductions. The dynamic capabilities framework represents an adaptation of this approach to the globally competitive environment of the business enterprise by adding greater specificity about not only the elements of the system but also the human element, namely, entrepreneurial managers. For the most part, dynamic capabilities studies have not explicitly invoked systems theory, but the two approaches are concordant. Reminders about the framework's intellectual debt to systems theory can serve as an aid in not missing the forest for the trees, focusing on key linkages and giving priority to certain (strategic) investments.

Systems theory is by no means the only predecessor to the dynamic capabilities framework. The intellectual origins of dynamic capabilities can also be traced to the work of Joseph Schumpeter, Edith Penrose, Herbert Simon, Nathan Rosenberg, Oliver Williamson, Israel Kirzner, Michael Tushman, Sidney Winter, and many other scholars of economics and business (Teece, 2011). Yet it is the logic of the systems approach that undergirds the entire edifice.

In line with the precepts of systems theory, managers in the dynamic capabilities framework view the enterprise and its extended market, technological, and regulatory environment as a whole, with many separate sub-systems to manage. Changes made in any aspect of the enterprise must align with - or be accommodated by - other elements. Examples include understanding how an effort to build new capabilities will affect existing capabilities and external ties, and 'orchestrating' the deployment of assets across all relevant domains of activity to implement a business model. A systems approach is also useful for shaping the external environment (Reeves, Levin, Harnoss, \& Ueda, 2017). Examples include managing an ecosystem of complementors or influencing decisions by relevant industry and government institutions.

The key is an integrated approach. Dynamically capable managers must promulgate a unifying strategic vision and facilitate collaboration across internal units. The goal is for the enterprise to function at least as efficiently as a healthy living organism.

The dynamic capabilities framework can be hard to master. One reason is that it does not lend itself to simple checklists or other distillations. Another reason is that, as discussed above, our education system favors specialization. However, once the framework is deeply understood, it can be the foundation of a more thorough analysis of the complex business landscape that can help guide decisions. 
The framework is still relatively young and in need of further elaboration and clarification. As it finds increasing application in industry, the experience gained will provide feedback for its improvement.

Some - perhaps even many - managers have an intuitive system-level grasp of the firm and its environment. By making the key elements and inter-relationships more explicit, the dynamic capabilities framework can help guide all managers toward improved prospects for sustained high performance longer term.

\section{ACKNOWLEDGMENTS}

The authors is grateful to Neil Kay, Greg Linden, and an anonymous reviewer for helpful comments and other assistance.

\section{References}

Adner, R., \& Helfat, C. E. (2003). Corporate effects and dynamic managerial capabilities. Strategic Management Journal, 24(10), 1011-1025.

Anderson, P. (1999). Perspective: Complexity theory and organization science. Organization Science, 10(3), 216-232.

Argyris, C. (1976). Single-loop and double-loop models in research on decision making. Administrative Science Quarterly, 21(3), 363-375.

Ashmos, D. P., \& Huber, G. P. (1987). The systems paradigm in organization theory: Correcting the record and suggesting the future. Academy of Management Review, 12(4), 607-621.

Augier, M., \& Teece, D. J. (2008). Strategy as evolution with design: The foundations of dynamic capabilities and the role of managers in the economic system. Organization Studies, 29(8-9), 1187-1208.

Augier, M., \& Teece, D. J. (2009). Dynamic capabilities and the role of managers in business strategy and economic performance. Organization Science, 20(2), 410-421.

Barney, J. B. (1991). Firm resources and sustained com-petitive advantage. Journal of Management, 17(1), 99-120.

Boulding, K. E. (1956). General systems theory - The skeleton of science. Management Science, 2(3), 197-208.

Brown, S. L., \& Eisenhardt, K. M. (1997). The art of continuous change: Linking complexity theory and time-paced evolution in relentlessly shifting organizations. Administrative Science Quarterly, 42(1), 1-34.

Burns, T., \& Stalker, G. M. (1961). The management of innovation. London: Tavistock.

Churchman, C. W. (1968). The systems approach. New York: Dell.

Eisenhardt, K. M., \& Martin, J. A. (2000). Dynamic capabilities: what are they? Strategic Management Journal, 21(10/11), 1105-1121.

Felix, R. (2003). A proposed taxonomy of management systems. Systems Research and Behavioral Science, 20(1), 21-29.

Holland, J. H. (1992). Complex adaptive systems. Daedalus, 121(1), 17-30.

Johnson, R. A., Kast, F. E., \& Rosenzweig, J. E. (1963). The theory and management of systems. New York: McGraw-Hill. Katz, D., \& Kahn, R.L. (1978). The social psychology of organizations (2nd ed.), New York: Wiley.

Latour, A. (2001). A Fire in Albuquerque sparks crisis for European cell-phone giants . Retrieved 29 January 2001 from https://www.wsj.com/articles/SB980720939804883010.

Levy, D. (1994). Chaos theory and strategy: Theory, application, and managerial implications. Strategic Management Journal, 15(S2), 167-178.

Nadler, D. A., \& Tushman, M. L. (1980). A model for diagnosing organizational behavior. Organizational Dynamics, $9(2), 35-51$.

Nadler, D. A., \& Tushman, M. L. (1997). Competing by design: The power of organizational architecture. New York: Oxford University Press.

Nelson, R.R., \& Winter, S.G. (1982). An evolutionary theory of economic change. Cambridge, MA: Harvard University Press.

Nonaka, I. (1994). A dynamic theory of organizational knowledge creation. Organization Science, 5(1), 14-37.

O'Connor, G. C. (2008). Major innovation as a dynamic capability: A systems approach. Journal of Product Innovation Management, 25(4), 313-330.

Porter, M. (1980). Competitive strategy. New York: Free Press. 
Priem, R. L., \& Butler, J. E. (2001). Is the resource-based 'view' a useful perspective for strategic management research? Academy of Management Review, 26(1), 22-40.

Reeves, M., Levin, S., Harnoss, J.D., \& Ueda, D. (2017). The five steps all leaders must take in the age of uncertainty. MITSloan Management Review, July 11. Retrieved from http://sloanreview.mit.edu/article/the-five-steps-all-leadersmust-take-in-the-age-of-uncertainty/.

Rousseau, D. M., \& Cooke, R. A. (1984). Technology and structure: The concrete, abstract, and activity systems of organizations. Journal of Management, 10(3), 345-361.

Rumelt, R. P. (1987). Theory, strategy, and entrepreneurship. In D. J. Teece (Ed.), The competitive challenge: Strategies for industrial innovation and renewal (pp. 137-158). Cambridge, MA: Ballinger.

Rumelt, R. (2011). Good strategy/bad strategy: The difference and why it matters. New York: Crown Business.

Samuel, Y., \& Jacobsen, C. (1997). A system dynamics model of planned organizational change. Computational \& Mathematical Organization Theory, 3(3), 151-171.

Schneider, M., \& Somers, M. (2006). Organizations as complex adaptive systems: Implications of complexity theory for leadership research. The Leadership Quarterly, 17(4), 351-365.

Simon, H. A. (1962). The architecture of complexity. Proceedings of the American Philosophical Society, 106(6), 467-482.

Teece, D. J. (1986). Profiting from technological innovation: Implications for integration, collaboration, licensing and public policy. Research Policy, 15(6), 285-305.

Teece, D. J. (2007). Explicating dynamic capabilities: The nature and microfoundations of (sustainable) enterprise performance. Strategic Management Journal, 28(13), 1319-1350.

Teece, D. J. (2010). Technological innovation and the theory of the firm: the role of enterprise-level knowledge, complementarities, and (dynamic) capabilities. In N. Rosenberg, \& B.H. Hall (Eds.), Handbook of the economics of innovation (Vol. 1, pp. 679-730). Oxford: North-Holland.

Teece, D. J. (2011). Achieving integration of the business school curriculum using the dynamic capabilities framework. Journal of Management Development, 30(5), 499-518.

Teece, D. J. (2012). Dynamic capabilities: Routines versus entrepreneurial action. Journal of Management Studies, 49(8), 1395-1401.

Teece, D. J. (2014). The foundations of enterprise performance: Dynamic and ordinary capabilities in an (economic) theory of firms. Academy of Management Perspectives, 28(4), 328-352.

Teece, D. J. (2015). Intangible assets and a theory of heterogeneous firms. In A. Bounfour, \& T. Miyagawa (Eds.), Intangibles, market failure and innovation performance (pp. 217-239). New York: Springer.

Teece, D. J. (2016). Dynamic capabilities and entrepreneurial management in large organizations: Toward a theory of the (entrepreneurial) firm. European Economic Review, 86, 202-216.

Teece, D. J. (2017). Business models and dynamic capabilities. Long Range Planning (in press), https://doi.org/10.1016/ j.lrp.2017.06.007.

Teece, D., Peteraf, M., \& Leih, S. (2016). Dynamic capabilities and organizational agility. California Management Review, 58(4), 13-35.

Teece, D. J, Pisano, G., \& Shuen, A. (1990). Firm capabilities, resources, and the concept of strategy. CCC Working Paper 90-8, Center for Research on Management, University of California, Berkeley.

Teece, D. J., Pisano, G., \& Shuen, A. (1997). Dynamic capabilities and strategic management. Strategic Management Journal, 18(7), 509-533.

von Bertalanffy, L. (1950). An outline of general system theory. British Journal for the Philosophy of Science, 1(2), 134-165.

Wernerfelt, B. (1984). A resource-based view of the firm. Strategic Management Journal, 5(2), 171-180. 